\title{
Educación, comunicación y cultura en la sociedad de la información: una perspectiva latinoamericana
}

\section{Martín Hopenhayn}

Oficial de Asuntos Sociales División de Asuntos Sociales CEPAL

mhopenhayn@eclac.cl
Los acelerados cambios que impone la sociedad de la informa-

ción en el ámbito productivo y comunicacional obligan a cambios fuertes y ágiles en la transmisión de conocimientos, la comunicación a distancia y el uso de información en los nuevos medios. Es necesario armonizar los saltos educativos con otro pilar de la sociedad de la información, a saber, el acceso al intercambio comunicacional por medios interactivos, donde no sólo se juega la competitividad, sino también la identidad cultural y, cada vez más, la participación ciudadana. De allí la importancia crucial de las mediaciones entre educación, cultura y nuevas tecnologías de la información y de la comunicación (TIC). Educar con nuevas tecnologías de información y conocimiento implica educar para imprimirle al uso de ellas sentidos que compatibilicen las nuevas formas de producir y trabajar con las nuevas formas de ejercer derechos, afirmar culturas, informarse, comunicarse a distancia y formar parte de redes. 


\section{La educación en el pedestal y en el banquillo}

La educación ha sido considerada por mucho tiempo el eslabón privilegiado para articular la integración cultural, la movilidad social y el desarrollo productivo. Una sociedad con altos niveles de escolaridad y buenos logros educativos tiende a ser más igualitaria en su estructura de ingresos (mediante la rentabilidad laboral de la educación), a contar con mayor cohesión cultural y mercados culturales más diversificados, y a crecer económicamente mediante saltos en la productividad y no en virtud de la sobreexplotación de recursos humanos o naturales. Sobre este carácter de "gran eslabón" de la educación existe hoy un consenso difundido, tanto en la literatura del desarrollo como en el debate político. ${ }^{1}$ Tras la pregunta por el tipo de desarrollo que podemos impulsar, sobreviene sin dilación la pregunta por el tipo de educación de que disponemos.

Conforme reza el decálogo del día, esta centralidad de la educación para la movilidad sociolaboral y el desarrollo productivo se hace hoy aún más decisiva, dada la importancia creciente de la innovación y el conocimiento en el proceso económico. Se argumenta que tener educación permite integrarse a la revolución informática, acceder a trabajos "inteligentes", y participar en las redes en que circula el conocimiento. Por el contrario, carecer de ella implica quedar recluido en el analfabetismo cibernético y restringido a ocupaciones de baja productividad y bajos salarios, privado del diálogo a distancia y de gran parte del intercambio cultural. El bienestar que augura la educación hoy ya no sólo remite a la posibilidad de generar a futuro mayores ingresos que los de nuestros padres, dado nuestro mayor capital humano, sino que también se refiere al uso de habilidades adquiridas para ejercer nuevas formas de ciudadanía, convivir constructivamente en el multiculturalismo, combinar el vínculo inmediato con el vínculo mediático, aggiornar en fin en la propia biografía el ideario emancipatorio de la modernidad.

Por otra parte, y en una dimensión más instrumental, la apertura global hace que las sociedades nacionales dependan cada vez más de su competitividad externa y ésta, a su vez, de la incorporación de inteli-

${ }^{1}$ Véase CEPAL/UneSco (1992); Hopenhayn y Ottone (2000). gencia y conocimiento renovado al sistema productivo. Esto lleva a que las opciones de desarrollo demanden grandes y veloces saltos educativos. No sólo es cuestión de contar con una población con más años de educación formal. Hay que aprender más, pero sobre todo aprender distinto. Es necesario adquirir las destrezas que se requieren hoy para incorporarse creativamente en las nuevas formas de trabajo, y para participar con racionalidad comunicativa en espacios de negociación y de toma de decisiones. La CEPAL y la UNESCO advertían ya hace una década que "al convertirse el conocimiento en el elemento central del nuevo paradigma productivo, la transformación educativa pasa a ser un factor fundamental para desarrollar la capacidad de innovación y la creatividad, a la vez que la integración y la solidaridad, aspectos claves tanto para el ejercicio de la moderna ciudadanía como para alcanzar altos niveles de competitividad" (CEPAL/ UNESCO, 1992, p. 119). ${ }^{2}$

Para esto se precisan activos que las personas tendrán que adquirir mediante distintas fuentes de producción y difusión de conocimientos. Combinaciones variables entre la educación formal y la industria cultural deberán constituir la oferta para promover disposiciones útiles en la sociedad de la información y la sociedad mediática: capacidad para expresar demandas y opiniones en medios de comunicación y aprovechar la creciente flexibilidad de éstos, iniciativa personal, disposición al cambio y capacidad de adaptarse a nuevos desafíos, manejo de racionalidades múltiples, espíritu crítico en la selección y el procesamiento de mensajes, capacidad de traducir información en aprendizaje y otros.

\footnotetext{
${ }^{2}$ En la misma obra y en igual sentido, se dice también: "La difusión de valores, la dimensión ética y los comportamientos propios de la moderna ciudadanía, así como la generación de capacidades y destrezas indispensables para la competitividad internacional (crecientemente basada en el progreso técnico), reciben un aporte decisivo de la educación y de la producción del conocimiento en una sociedad. La reforma del sistema de producción y difusión del conocimiento es, entonces, un instrumento crucial para enfrentar tanto el desafío en el plano interno, que es la ciudadanía, como el desafío en el plano externo, que es la competitividad. Se entiende así que esta dimensión sea central para la propuesta de la CEPAL sobre transformación productiva con equidad" (p. 17).
} 
Estas nuevas destrezas no son mera programación sobre una tabla rasa. No sólo se trata de adquirir conocimientos, sino de hacer del aprendizaje un proceso interactivo, donde el énfasis esté puesto mucho más en la producción de nuevas síntesis cognoscitivas en el estudiante que en la adquisición de información acabada. Todo esto sugiere protagonismo, interacción y espíritu crítico. La misma redefinición del aprendizaje en la transmisión de estas destrezas supone un cambio paradigmático en el estilo de la educación: de la memorización a la comprensión, de la incorporación de información a la discriminación de mensajes, de la adquisición enciclopédica a la adquisición selectiva, del disciplinamiento mecánico a la autonomía responsable, del aprender al aprender a aprender.

En una perspectiva cultural, la educación ostenta un rango más ambiguo. Por una parte se le atribuye históricamente un rol poco grato, subordinado a los proyectos de homogeneización cultural, bajo el modelo de un Estado-Nación que siempre buscó la coincidencia de la unidad territorial con la unidad simbólica. De este modo, la más reciente defensa del pluralismo cultural y la diversidad de identidades se ha encargado de poner sobre el tapete una retrospectiva crítica del rol de la educación. Se le atribuye un cierto aire de cruzada iluminista, que habría pretendido la aculturación de las minorías étnicas y la imposición de una racionalidad común, para consolidar la unidad político-territorial a través de un mayor disciplinamiento de los sujetos en los códigos de modernidad y en la adhesión a valores nacionalistas. En otra línea crítica, se le objeta a la educación —o a sus estilos más tradicionales— que en lugar de estimular las potencialidades de los educandos, atrofie su creatividad y reprima sus emociones más genuinas.

Pero también se ha reinterpretado positivamente el rol cultural de la educación, entendiendo que es la base desde la cual se puede repensar críticamente la realidad, idear nuevos proyectos colectivos y aprender a vivir en un mundo multicultural. El aprendizaje de la diferencia o de la pluralidad no debe entenderse como una materia más (al estilo de la geografía, la historia o la antropología). Se trata de reformular la articulación o el cruce entre el currículo que viene desde arriba y las identidades culturales que llegan desde abajo, o entre materias de aprendizaje y sujetos de aprendizaje; de la misma manera que se trata de aterrizar contenidos globales en realidades locales e, inversamente, reformular contenidos desde los mundos de vida que traen los alumnos a las salas de clases. Esta articulación no se resuelve en las altas esferas de la planificación educacional, sino en el contexto más particular de cada escuela. Más que contenidos curriculares, lo que se requiere es generar una disposición general al cambio en las formas de aprender, comunicarse y producir. "El futuro profesional — advierte Alain Touraine- es tan imprevisible, e implicará brechas tan grandes en relación a lo que ha aprendido la mayoría de quienes hoy asisten a la escuela, que debemos, antes que nada, solicitar a la escuela que los prepare para aprender a cambiar más que formarlos en competencias específicas que probablemente estarán obsoletas o serán inútiles para la mayor parte de ellos a corto plazo" (Touraine, 1997, p. 328).

Pensar la diferencia es pensar al propio educando como "traspasado" por la diferencia, y pensar al otro como interrogación sobre sí mismo. Esto es válido en el encuentro entre identidades culturales distintas, pero también en la relación entre profesores y alumnos, y entre alumnos y alumnas. El aprendizaje de la diferencia se convierte así en aprendizaje de ciudadanía: aprender a ponerse en el lugar del otro y a ver con los ojos del otro. Como señala Magdaly Téllez, "sin hacer intervenir tal relación (la alteridad) el reconocimiento de la diferencia se hace puro registro de la pluralidad, y de lo que se trata es que la diferencia se resuelva en experiencias que construyen relaciones democráticas y ciudadanía (...) lo que está en juego no es sólo el problema de la existencia de los otros como diferencia histórica y culturalmente producida, sino el hecho de que también lo propio se desterritorializa y se reterritorializa y, en consecuencia, se resignifica en el sentido de que deja de ser una identidad clausurada en términos de pertenencia a una nación, a una raza, a una clase social, a una organización política, a una profesión, a una comunidad académica, etc., para hacerse espacio plural en el que se entrecruzan múltiples narrativas y lenguajes" (Téllez, 1998, pp. 136-137). La apertura a la diferencia no es, pues, sólo un ejercicio políticamente correcto de tolerancia ante los demás. Implica un proceso de transformación de los sujetos mediante el desarrollo de la capacidad de ponerse en la piel de los otros, enriquecerse con las cosmovisiones de otros, ampliar la sensibilidad propia con la que aporta la experiencia de la diferencia. En este sentido, "educar en el respeto a la diversidad, el reconocimiento del otro y el ejercicio de la solidaridad, son condiciones para ampliar y enriquecer la propia identidad" (Cubides, 1998, p. 45).

Los retos desde la cultura a la educación también se exacerban con el dinamismo de las identidades en la interacción mediática: la convivencia en la diferencia 
por el aumento de migrantes y familias de migrantes, la segmentación de gustos ante la oferta expandida de los mercados culturales, la mayor visibilidad de la cuestión étnica en la política y en los medios de comunicación, las hibridaciones entre lo nuevo y lo viejo y entre lo local y lo externo. Todo esto mina las formas rígidas y generales en que la educación y la cultura se han articulado secularmente, e interpela al sistema educativo precisamente en aquellos referentes históricos que lo rigieron por muchas décadas: la misma educación para todos, programas decididos centralmente y de larga vigencia, concepto universal y clásico de la cultura que se debe transmitir, y unificación cultural a través de la educación formal. Tanto los procesos de aprendizaje como la convivencia escolar se ven tensados entre un imaginario educacional teñido por aspiraciones unificantes, y nuevas realidades en el campo del conocimiento y de la vida cotidiana que pueblan la cabeza de los alumnos de muchos textos cruzados. Estas tensiones piden nuevas síntesis y mapas cognitivos, y hasta ahora el sistema formal de educación no ha tenido la suficiente creatividad para asumir el reto.

Educar conforme a los procesos y contextos culturales de los educandos nos devuelve a algunas de las premisas de la pedagogía crítica que Paulo Freire planteó en los decenios de 1960 y 1970, en el sentido de acercar la educación a las realidades socioculturales de los educandos y a una perspectiva crítica y transformadora de la realidad que ellos viven. ${ }^{3}$ En un estudio que resume investigaciones de casos sobre aplicaciones de Internet en escuelas de bajos recursos en América Latina, se plantea que en escuelas rurales de Argentina "el peso del éxito recayó en la capacidad de incorporar el Internet a las necesidades y ámbitos de las comunidades locales (...) bajo principios que permitan un intercambio horizontal y equitativo del conocimiento" (Bonilla, 2001, p. 10).

José L. González propone el "planteamiento crítico" como ejercicio pedagógico, basado en un modelo constructivista de la enseñanza y el aprendizaje. Su objetivo, advierte, es "decodificar mensajes y conte-

\footnotetext{
${ }^{3}$ Según García y Pruyn (2001, p.6): 'En el corazón del enfoque de Freire (...) los estudiantes son motivados para constituirse en analistas y agentes críticos' y 'los maestros críticos que siguen esta filosofía son alentados para que involucren a los educandos en discusiones e investigaciones sobre sus realidades vividas y situaciones personales. Las preocupaciones, necesidades y experiencias personales de los estudiantes están en el centro de este proceso'. [El texto reproducido aquí, entre comillas simples, corresponde a una traducción del inglés efectuada por el autor del presente artículo.] Véase también Freire y Macedo (1987).
}

nidos, analizando, jerarquizando y ordenando la información difundida por los medios y por las nuevas tecnologías de la información", por lo cual "la introducción y asentamiento de la materia de educación en comunicación y medios en las aulas significa abrir la escuela al entorno" (González, 2000, pp. 4 y 5). La idea es utilizar los medios de comunicación en prácticas educativas como medios de expresión y de cuestionamiento, vale decir, como una práctica pedagógica que sea a la vez un ejercicio preparatorio de participación ciudadana.

Por otra parte se defiende la importancia de la educación para el ejercicio de la ciudadanía. Se sostiene al respecto que la centralidad progresiva del conocimiento y la educación para el desarrollo inciden significativamente en la dinámica de un orden democrático, donde la economía y la institucionalidad política se relacionan cada vez más con el uso ampliado del conocimiento, la información y la comunicación. En una proporción creciente, el procesamiento de demandas en el juego deliberativo va a realizarse a través de las nuevas tecnologías informáticas y comunicacionales; y cada vez más el uso de servicios y beneficios estatales o públicos va a obligar a los ciudadanos a estar informados, desarrollar capacidad de gestión y operar con los códigos de la sociedad de la información. Todo esto hace que la educación y el conocimiento también sean cada vez más centrales en la promoción de las nuevas formas de ciudadanía.

Así, entre viejas y nuevas funciones, la educación aparece como una bisagra para compatibilizar tres grandes aspiraciones de la modernidad: la producción de recursos humanos; la construcción de ciudadanos para que actúen en la política y en la vida pública, y el desarrollo de sujetos autónomos. Utilizo aquí deliberadamente las palabras producción, construcción y desarrollo al aludir respectivamente a recursos humanos, ciudadanos y sujetos autónomos. Creo que este detalle semántico diferencia y a la vez complementa los componentes instrumentales, políticos y éticos en el desafío de educar para la vida moderna. La modernidad alberga en su historia y en sus promesas precisamente esta triple dimensión para sus moradores: crecer en productividad, en ejercicio de la ciudadanía y en autonomía personal.

Tenemos, pues, que la educación está disfrutando en el pedestal de la consagración y sufriendo en el banquillo del acusado. Existe conciencia de los anacronismos y disfuncionalidades acumulados en el sistema educativo. Las banderas de la autonomía, la descentralización, la selectividad, la modernización, la 
flexibilización y otras, flamean en reuniones ministeriales, artículos de prensa y documentos finiseculares. En boca de idéologos de la educación, futurólogos, teóricos y políticos del desarrollo, y expertos de los organismos internacionales, se hace cada vez más frecuente una proclama y un imperativo, a saber: que es tarea impostergable y central reformar los sistemas de educación formal en América Latina y constituirlos en cimientos para "relanzar" el desarrollo. Todo ello implica una radical readaptación de los contenidos, de la pedagogía y de la planificación educativos. Tarea, claro está, nada sencilla, pues obliga a reprogramar hábitos muy asentados en ministerios, secretarías, plana docente y personal a cargo de establecimientos educacionales.
En este impulso educativo donde todos confluyen, los requerimientos instrumentales de la modernización productiva van de la mano con los otros, más complejos, de la subjetividad y la cultura. Existe el riesgo de poner muchas expectativas en un proceso cuya calidad y logro depende de tantas variables, como es el caso de la educación. Y el riesgo, también, de una hipóstasis de la educación en un momento histórico en que se hacen más difusos los canales que articulan el sistema educativo con los mercados laborales, y donde la urgencia por inocular destrezas instrumentales para la competitividad acabe por devorar otros aspectos formativos que requieren ritmos distintos, y que tienen que ver con el aprendizaje para vivir las emociones y procesar las biografías personales.

\section{II}

\section{Dónde estamos parados}

\section{en términos educativos}

Durante la última década, América Latina ha alcanzado altos niveles en la matrícula escolar, por lo que se ha llegado a considerar que este problema está casi resuelto en el nivel primario. La tasa neta de escolarización primaria para la población de ocho años llega a 96,3\%, aunque la preescolar sólo alcanza al $23 \% .{ }^{4} \mathrm{Y}$ en la educación superior, la tasa de asistencia no rebasa el $35 \%$ (como promedio nacional) en país alguno de América Latina. Además, los países de la región enfrentan un problema grave de deserción escolar durante la educación secundaria y antes de completarla. Baste comparar, para confirmarlo, las altas tasas de matrícula en la enseñanza primaria con aquellas muy inferiores en la secundaria. Esto es tanto más grave si consideramos que, en materia de relación entre educación y bienestar, la CEPAL ha señalado en diversos documentos que se requieren entre 11 y 12 años de educación formal para contar con claras posibilidades de salir de la pobreza o de no caer en ella gracias al acceso a empleos con remuneraciones o ingresos suficientes. Sin embargo, en la región el $40 \%$ de los niños no terminan la escuela primaria, y entre el $72 \%$ y $96 \%$

\footnotetext{
${ }^{4}$ Los datos que aquí se presentan sobre cobertura educativa se han consultado en la División de Estadística y Proyecciones Económicas de la CEPAL, en la página web de la UNESCO, y en UNESCO (2000a).
}

de las familias pobres tienen jefes de hogar con menos de nueve años de educación formal, mientras el $80 \%$ de los jóvenes urbanos tienen padres con menos de 10 años de educación formal, lo que los hace especialmente proclives a no alcanzar el nivel educativo requerido para sortear la pobreza (CEPAL, 2000).

Además enfrentamos un grave problema de desigualdad social en la educación. Según datos de la CEPAL, la brecha de logros entre los cuartiles extremos de ingresos ( 1 y 4 ) se acrecentó en todos los países latinoamericanos durante el decenio de 1990. Vale decir, la educación media y la superior mantienen un sesgo clasista, ${ }^{5}$ contrariamente a lo sucedido con la educación primaria. Esto es grave, ya que las estadísticas muestran una correlación positiva entre más educación y más equidad, lo que quiere decir que los países con logros escolares más difundidos también tienen menores diferencias de ingresos y son más igualitarios en su estructura social. Hay fuertes disparidades de logros educacionales (tanto en número de años estudiados como en calidad del aprendizaje) por grupos de ingreso, que condenan a la reproducción de las inequidades

\footnotetext{
${ }^{5}$ Salvo en países de la región, como los del Cono Sur, donde la cobertura de la educación secundaria es claramente mayoritaria.
} 
sociales. A mayor segmentación de los logros, más rígida será la estructura de grupos sociales a futuro, y más segmentadas estarán las oportunidades de las nuevas generaciones en materia de movilidad social, desarrollo productivo y capacidades para el ejercicio ciudadano y el diálogo intercultural. En una sociedad centrada en la información y el conocimiento, las posibilidades de los distintos grupos para llevar a cabo sus proyectos de vida según sus propios valores y visiones de mundo, dependen en importante medida de la cantidad y calidad de la educación a la que puedan acceder. Al menos así reza el decálogo.

De este modo, por ejemplo, en los últimos 30 años naciones como Cuba, España y Portugal ampliaron la cobertura secundaria y terciaria de manera sostenida y acelerada y muy por encima del promedio latinoamericano. Y contra lo que proclama el discurso emergente de la educación, que asocia la mayor eficiencia a la menor intervención estatal directa, dichos países alcanzaron esos ritmos acelerados de expansión con un sistema de educación pública y una fuerte planificación estatal. ${ }^{6}$

La pregunta, por lo tanto, es si estos rezagos y el ritmo moderado con que se superan son inevitables dada la limitación de los recursos disponibles. La respuesta es negativa si se compara el ritmo de expansión hacia los niveles secundario y superior en América Latina con el que exhiben los países de la Organización de Cooperación y Desarrollo Económicos (OCDE) y del sudeste asiático (cuadro 1).

Como se observa en el cuadro 1, entre 1985 y 1997 se invirtió la relación entre los países del sudeste asiático recientemente industrializados y los países de América Latina y el Caribe: los primeros partieron con rezagos y en doce años lograron una situación educativa claramente más avanzada no sólo en matrícula, sino también en su desempeño en pruebas estandarizadas por nivel, horas de enseñanza efectiva al año y otros indicadores. En el mismo lapso los países de la OCDE, cuya situación inicial era bastante mejor que la latinoamericana, se distanciaron aún más y a un ritmo muy acelerado. América Latina muestra, además, rezagos en la duración de la enseñanza secundaria (más corta en la región que en otros grupos de países) y en la extensión de la educación obligatoria. Además, en los países de la OCDE el $85 \%$ de los jóve-

\footnotetext{
${ }^{6}$ No defiendo el estatismo en este punto sino relativizando la euforia privatizadora que en algunos países tiende a darse en el ámbito de los servicios sociales.
}

nes completa estudios secundarios, mientras que en América Latina menos de un tercio de los jóvenes logra ese nivel de acreditación.

También hay diferencias entre alumnos latinoamericanos y de países industrializados en la calidad del aprendizaje de matemáticas y manejo del lenguaje, medida por pruebas estándares de lectura, matemáticas y ciencias, en claro detrimento de nuestros países (cuadro 2). Disminuir esta brecha es tanto más difícil si se piensa que los países industrializados —que reúnen el 25\% de los alumnos del mundo-gastan seis veces más en formación de capital humano que los países en desarrollo - donde vive el 75\% restantey que hacia 1999 el mundo desarrollado, con el 15\% de la población mundial, tenía el $88 \%$ de los usuarios de Internet (Brunner, 1999, p. 2).

La proporción de oferta y matrícula de la educación técnica en el nivel secundario superior (vale decir, en los dos o tres últimos años del nivel secundario) exhiben diferencias significativas, siendo mucho más alta en los países de la OCDE y del sudeste asiático que en América Latina. Estas diferencias son muy importantes, porque el nivel secundario superior es clave tanto para mejorar las condiciones generales de la fuerza de trabajo como para lograr efectos virtuosos sobre la equidad y la movilidad social. La experiencia de algunos países europeos muestra también que la mayor y mejor oferta de educación técnico-profesional en este nivel educativo, como también en el nivel superior no universitario, tiene efectos muy positivos sobre el destino de los estudiantes cuando ingresan al mercado de trabajo, y permiten elevar la productividad general. Finalmente, las bajas cobertura y calidad de estas alternativas implica desaprovechar la opción de capacitar ampliamente en el uso productivo de las tecnologías de la información y la comunicación, las que, en tanto sean amigables y motiven a los jóvenes en edad escolar, podrían ser objeto de cursos de capacitación masivos en el nivel secundario superior de tipo vocacional o técnico-profesional. Este espacio o segmento educativo es, posiblemente, el más idóneo para formar en nuestros países a una generación de jóvenes con mayores capacidades de acceso, uso y creatividad en el campo de tales tecnologías, y hacerlo masivamente. Esto significaría avanzar cuantitativa y cualitativamente en la transición hacia la sociedad informática y en la formación de capacidades productivas y de comunicación, de ejercicio ciudadano y de conexión con el mundo.

Otra brecha fundamental está dada por los ingresos de los maestros, pues es claro que las condiciones 
CUADRO 1

Grupos de países: Comparación de la matrícula en educación secundaria y superior entre América Latina y el mundo industrializado, 1985 a 1997

(Porcentajes)

\begin{tabular}{|c|c|c|c|c|c|c|}
\hline \multirow[t]{3}{*}{ Grupos de países } & \multicolumn{6}{|c|}{ Tasas brutas de matrícula } \\
\hline & \multicolumn{3}{|c|}{ Educación secundaria } & \multicolumn{3}{|c|}{ Educación terciaria } \\
\hline & 1985 & 1997 & $\begin{array}{l}\text { Incremento porcentual en } \\
\text { tasas de matrícula }\end{array}$ & 1985 & 1997 & $\begin{array}{l}\text { Incremento porcentual en } \\
\text { tasas de matrículas }\end{array}$ \\
\hline América Latina y el Caribe & 50,2 & 62,2 & 12,0 & 15,8 & 19,4 & 3,6 \\
\hline Países de la OCDE & 92,3 & 108,0 & 15,7 & 39,3 & 61,1 & 21,8 \\
\hline $\begin{array}{l}\text { Economías asiáticas de } \\
\text { industrialización reciente } \\
\text { Este y sudeste asiáticos }{ }^{\mathrm{b}}\end{array}$ & 57,3 & 73,1 & 15,8 & 14,8 & 30,5 & 15,7 \\
\hline
\end{tabular}

Fuente: Beverley Carlson, con base en datos de UNESCO (2000b).

a China, Hong Kong, Malasia, República de Corea, Singapur y Tailandia.

b Sólo países en desarrollo (no industrializados, incluyendo los de industrialización reciente o incipiente).

CUADRO 2

Países iberoamericanos: Posición relativa en estudios internacionales de calidad de la educación

\begin{tabular}{|c|c|c|c|}
\hline Estudio & Países participantes & Países iberoamericanos & Posición relativa \\
\hline LLECE, 1997 & 13 & 13 & $\begin{array}{c}\text { Los puntajes medios del país } \mathrm{N}^{\circ} 1 \\
\text { distan entre } 1,5 \text { y } 2,0 \text { desvíos estándares } \\
\text { de los } 12 \text { países restantes }\end{array}$ \\
\hline TIMSS 1996 & 41 & 3 & 31,37 y 40 \\
\hline TIMSS 1999 & 38 & 1 & 35 \\
\hline IALS 1998 & 22 & 2 & 19 y 22 \\
\hline IALS 1998 & 22 & 2 & 21 y 22 \\
\hline
\end{tabular}

Fuente: Laboratorio Latinoamericano de Evaluación de la Calidad de la Educación (LLECE), International Adult Literacy Survey (IALS), The Third International Mathematics and Science Study (TIMSs) y OCDE (2001).

docentes inciden de manera decisiva en los procesos de aprendizaje de los alumnos. Cabe considerar que, en promedio, el ingreso anual de los maestros de la enseñanza pública en la región alcanza sólo a una quinta parte del que obtienen en los países desarrollados los profesores con igual número de años de experiencia y horas trabajadas. Si bien esta diferencia guarda relación con la que existe entre los productos internos brutos (PIB) de ambos grupos de países, implica una disparidad sustancial en las condiciones en que los docentes se desenvuelven para enseñar y para actualizar sus conocimientos y metodologías. Además, la relación entre el ingreso de los docentes y el de otros grupos de profesionales es menor en los países industrializados que en la región.

¿De qué manera estas diferencias en niveles de formación recién consignadas entre América Latina y parte importante del mundo industrializado (o de industrialización reciente) tienen su correlato en brechas culturales? La experiencia internacional y la situación mundial puede inducir al menos a tres conjeturas plausibles.

En primer lugar, la globalización tiene un impacto muy fuerte sobre las culturas locales, tanto positivo como negativo. Positivo, porque la globalización comunicacional, sobre todo con las nuevas tecnologías, permite a las culturas locales operar como interlocutores activos en el diálogo planetario, planteando con más fuerza sus identidades, demandas y visiones del mundo. Negativo, porque se producen relaciones de dominio, hegemonía y aculturación en este gran baile de símbolos y mercancías que fluyen sin fronteras. En ese contexto de doble signo, el acceso al conocimiento parece ser una clave para potenciar el aspecto positivo y mitigar los efectos negativos. A mayor y mejor educación, hay más manejo de la interacción a distancia, más capacidad para gestionar y movilizar las propias demandas de afirmación de identidad, de más 
presencia en el diálogo global, de más impacto sobre la "sociedad civil global". ?

En segundo lugar, las diferencias en niveles de formación generan también una mayor distancia entre el mundo industrializado y el mundo en desarrollo, y esta distancia a su vez parece cada vez más difícil de revertir, condenando al mundo en desarrollo al triste rango de patio trasero de la globalización. Tal situación puede surtir distintos efectos, todos catastróficos: de retraimiento y/o atrincheramiento cultural, de desánimo masivo, de pérdida de utopías y proyectos colectivos y, lo que más se conoce, de rápido ascenso de fundamentalismos de distinto tipo como forma de reaccionar y de compensar la exclusión y el estancamiento.

En tercer lugar, la educación constituye la herramienta más masiva, sistemática e instalada para socializar a las nuevas generaciones en el multiculturalismo, el nuevo imaginario democrático global, el discurso y la práctica de los derechos humanos, el aprendizaje en la diferencia, y la adaptación de saberes universales a sensibilidades personales o grupales. ${ }^{8}$ Además, a medida que los propios educadores van rectificando sesgos etnocéntricos propios, y que la educación revierte su histórico rol de homogeneización cultural, es posible que los nuevos procesos de aprendizaje sean de apertura a otros radicalmente distintos. Más aún, tematizando y polemizando la aculturación u homogeneización históricas en la sala de clases, es posible promover la afirmación de las identidades que concurren a esa misma sala.

¿Y qué hacen los Estados ante esta situación, en que la progresión de los logros educativos ha aumentado a un ritmo menor que el deseado, la calidad de la educación hace agua por distintos frentes, ${ }^{9}$ la alta desigualdad de logros debida a condiciones de la deman-

\footnotetext{
${ }^{7}$ Algo que suele desconocerse cuando se quiere explicar la mayor movilización de grupos indígenas latinoamericanos en las últimas dos décadas es la formación universitaria de sus nuevos líderes. ${ }^{8}$ Obviamente, dependiendo de qué tipo de educación se tenga. Pero puede ser un instrumento orientado a estos fines.

${ }^{9}$ El rango de problemas asociados a la calidad es muy amplio, y se puede incluir, entre otros, los siguientes: la falta de pertinencia de los contenidos pedagógicos frente a los mundos de vida y los futuros laborales de los educandos; métodos didácticos anacrónicos en los que persiste un enfoque memorístico y frontal poco coherente con las nuevas formas de adquirir y difundir conocimientos; deterioro de la calidad docente debido a malas condiciones de vida y de trabajo y al bajo reconocimiento simbólico; falta de equipamiento adecuado (textos, computadoras, soportes audiovisuales); jornadas escolares muy cortas o aulas sobrepobladas; falta de apoyo a las condiciones de aprendizaje en los hogares, y carencia de alternativas intermedias de capacitación técnica.
}

da y de la oferta persiste cuando se desglosa por estratos socioeconómicos y por corte rural-urbano, ${ }^{10}$ y la gestión del sistema educativo ha entrado en una crisis profunda y un proceso de reforma exhaustivo? ${ }^{11}$

Estos problemas diagnosticados han llevado, a partir del decenio de 1980, a casi todos los países latinoamericanos a embarcarse en procesos de reforma, incrementando recursos humanos y monetarios con el fin de impulsar saltos cualitativos en la formación y el aprendizaje de las nuevas generaciones. Si bien los énfasis en cada país son distintos, ${ }^{12}$ el conjunto de las reformas apunta a intervenir sistémicamente en los más variados aspectos de la educación, a saber: los contenidos curriculares y los métodos pedagógicos; los mecanismos de financiamiento del sistema; la redistribución de funciones entre el sector público y el privado; la descentralización de la gestión educativa, entregando responsabilidades al municipio y a la propia escuela; la revisión de prácticas pedagógicas y la evaluación de logros, y en medida incipiente, la adecuación curricular a nuevos patrones productivos y a las condiciones socioculturales de los educandos.

Sin embargo, también se han levantado voces críticas en los distintos países de la región frente a los sesgos adquiridos por las reformas en curso. Se señala que las reformas son excesivamente tecnocráticas, concentrándose en mecanismos de financiamiento y gestión, pero no en contenidos y procesos de aprendizaje reales. Se objeta que el énfasis en la calidad ha hecho descuidar la necesidad apremiante de mayor equidad social en los aprendizajes y logros educativos, y que las nue-

\footnotetext{
${ }^{10}$ Por el lado de la demanda, el clima educacional de los hogares gravita de manera decisiva en el logro educativo de los alumnos: familias con bajos niveles educacionales (que en general son de ingresos bajos o medios bajos) tienden a reproducir bajos logros en los hijos. Además, las familias pobres no cuentan con computador ni con acceso a las Tic, lo que plantea una desventaja cada vez más dramática en el desarrollo de nuevas destrezas en el hogar. Por el lado de la oferta, el creciente gasto privado en educación, debido a la importancia creciente que las familias asignan a la formación de los hijos, acrecienta cada vez más la diferencia entre la calidad educativa de los colegios privados y la de los públicos.

${ }^{11}$ En parte porque el fuerte incremento de la población matriculada en las últimas cinco décadas ha hecho colapsar un sistema diseñado para otra escala; en parte porque la burocracia estatal y el comportamiento corporativo del sistema habrían acumulando ciertos "vicios históricos" que merman la eficiencia de la política pública; en parte porque es necesario abrir el sistema a aportes potenciales del sector privado y a la iniciativa de otros agentes para mejorar sus prácticas, y en parte por la necesidad de focalizar recursos en los grupos más vulnerables y de adaptar los contenidos a los contextos socioculturales de los educandos.

${ }^{12}$ Por ejemplo, no todos comparten la euforia por la descentralización del sistema o por el protagonismo de los agentes privados.
} 
vas formas de combinar la iniciativa pública y privada han llevado a una mayor segmentación de la calidad de la oferta, que puede significar la reproducción o exacerbación de contrastes sociales en el futuro y una menor responsabilidad o fiscalización del Estado ante las escuelas y universidades. Se afirma que la calidad de la docencia no ha mejorado, porque los docentes siguen siendo profesionales mal pagados y mal considerados, y porque no se ha logrado acercar los contenidos ni los estilos de la educación formal a los cambios culturales que han vivido en las últimas décadas los educandos, sobre todo aquellos relacionados con el consumo mediático y con nuevos imaginarios juveniles. Se argumenta que las reformas tienden a privilegiar el aprendizaje de saberes funcionales al desarrollo tecnológico y al desempeño productivo futuro, mutilando aspectos menos instrumentales del aprendizaje, como la expresividad y la autocomprensión. Y se plantea la necesidad de volver a la raíz del problema educacional, preguntándose por el sentido de la educación más que por su utilidad y entendiendo que al centrarse demasiado en los rendimientos se puede olvidar lo fundamental: el desarrollo emocional e intelectual de los educandos.

\section{III}

\section{Diferencias de acceso y diferencias de sentido: los cruces entre la educación y las tecnologías de la información y la comunicación}

\section{Diferencias de acceso y caminos para corre- girlas}

Si la educación de calidad es uno de los pilares para promover la incorporación masiva y sostenida a la sociedad del conocimiento (y a la globalización centrada en dicho modelo), otro pilar lo constituye el acceso al intercambio comunicacional, donde no sólo se juega la productividad laboral, sino también la integración simbólica. Los indicadores de densidad de la industria y el consumo audiovisuales, así como de densidad informática y de conectividad, ${ }^{13}$ son cada vez más significativos para el análisis de las tendencias en el campo cultural, sobre todo porque las tecnologías de la información y la comunicación son y serán cada vez más gravitantes para promover la visibilidad cultural, vale decir, para que las distintas expresiones culturales puedan tener presencia en el diálogo global mediático, así como también en la arena política interna y en los espacios públicos.

En el plano interno, las industrias de la comunicación constituyen la vía más importante de acceso al espacio público para amplios sectores sociales que carecen de espacios de expresión y, con ello, para ejer-

\footnotetext{
13 Por conectividad se entiende el acceso a redes electrónicas interactivas.
}

cer activamente la participación ciudadana. En este sentido, hacia el fin de 2002 la densidad comunicacional en la región era heterogénea, pues variaba de un medio a otro: mientras la mayoría de los hogares tenía televisión, el $16 \%$ de los hogares contaba con telefonía fija; de la población, el $20 \%$ contaba con telefonía celular, el $8 \%$ con acceso a Internet y sólo el $0,3 \%$ con acceso a banda ancha (Hilbert, 2003). Estas cifras indican que mientras una parte significativa de la población tiene acceso a información, imágenes, contenidos y mensajes a distancia que otros emiten (y frente a los cuales sólo ostentan la condición de receptores), una parte menor tiene la posibilidad de comunicarse a distancia en una relación individual, y una parte todavía más reducida accede a medios interactivos a distancia que les permite actuar como emisores frente a grupos más extensos.

Si la conectividad a medios interactivos constituye un indicador determinante de la participación en la sociedad de la información y el conocimiento, los contrastes observados en 2002 entre los Estados Unidos y América Latina resultan impactantes (UIT, 2003): mientras en el primer caso había 63 computadores personales, 54 usuarios de Internet y 37 hosts $^{14}$ por cada 100

\footnotetext{
14 Hosts: computadores que almacenan la información de páginas
} Web. 
habitantes, entre los países latinoamericanos Uruguay llevaba la delantera en hosts (2,1 por cada 100 habitantes), Chile en usuarios (20) y Costa Rica en número de computadores personales $(17,02)$.

Los contrastes en el acceso a bienes comunicacionales "de ida y vuelta" (como telefonía e Internet) son inquietantes cuando se comparan las distintas regiones del mundo. Por el momento, el 20\% de la población global que vive en los países más pobres sólo cuenta con un $1,5 \%$ de las líneas telefónicas, mientras el 20\% de la población de los países más ricos cuenta con el $74 \%$ de ellas. En lo que a acceso y presencia en Internet se refiere, también preocupa que, según el informe sobre desarrollo humano en 1999 (PNUD, 1999), sólo un $2,4 \%$ de la población mundial accedía a Internet, básicamente en naciones industrializadas, y un $80 \%$ de la comunicación en la red se realizaba en inglés (Brunner, 1999).

El rezago latinoamericano se ilustra además por el hecho de que en 1999 la región representó el 8\% de la población mundial y su incidencia en el ciberespacio alcanzó sólo al 4\%; aunque contribuye con alrededor del $7 \%$ al PIB mundial, sólo aporta el $1 \%$ al comercio mundial que se hace por vía electrónica (Hilbert, 2001a). ${ }^{15} \mathrm{En}$ contraste con estos datos desalentadores, la región ha exhibido en los últimos años, en comparación con las otras regiones del mundo, la más rápida expansión relativa de la "comunidad de Internet". En cuanto a los hosts, mientras en 1999 su número aumentó 30\% en Europa, $61 \%$ en Asia y $74 \%$ en América del Norte, el alza en América Latina fue de 136\% (Hilbert, 2001a). Este crecimiento en materia de acceso refleja también una expansión del comercio electrónico, que comenzó hacia 1998 y alcanzó un nivel de 20.000 millones en 2002, lo que ya representa $1 \%$ del PIB de América Latina (CEPAL, 2003). En pocas palabras, estamos mal pero no vamos tan mal.

Si estar fuera de la red es estar simbólicamente a la intemperie o en la sordera, las asimetrías entre conectados y desconectados marcan una brecha casi ontológica. Por otra parte, la conectividad tiene un sesgo fuertemente urbano y metropolitano: en Argentina, hacia 1999 , el $87 \%$ de los sitios Web y sus domicilios físicos estaban radicados en la Capital Federal y el Gran Buenos Aires. En Chile la concentración

\footnotetext{
15 En 2000, Brasil absorbía el 69\% del comercio electrónico total dentro de América Latina (Hilbert, 2001b); en general, el incremento previsto de este comercio es exponencial: desde casi cero en 1999 a cerca de 100.000 millones de dólares en 2004 (Hilbert, 2001b).
}

de usuarios de Internet en Santiago es proporcionalmente mayor que la de población y la del PIB, y el porcentaje de correo electrónico que concentra la capital duplica el porcentaje de población nacional que ella alberga. En cuanto a la segmentación por estratos sociales, de acuerdo a las estimaciones de Emarketers, a comienzos de 2000 estaba conectado el $18,1 \%$ del $15 \%$ más rico de la población latinoamericana, pero sólo el 2,7\% de la población latinoamericana total. Se prevé que en 2004 estará conectado el 68,9\% del 15\% más rico de la población latinoamericana de 14 años y más, pero sólo el $10 \%$ del total de la población latinoamericana de 14 años y más (Hilbert, 2003). Según la misma fuente, en Brasil se espera que hacia 2004 el $81,8 \%$ del $15 \%$ más rico de la población esté conectado, porcentaje que sería de $12,3 \%$ respecto del total de la población. Si la red es el nuevo eje de la participación ciudadana, ¿qué clase de democracia participativa se puede esperar con estos indicadores de segmentación?

Finalmente, Internet está planteando segmentaciones etarias sorprendentes. En Brasil, según datos de 1999, el 15,8\% de los jóvenes de 14-19 años había usado Internet, contra el 11,3\% de la población de 2035 años, el 5,6\% de la de 36-45 años y el 3\% de los mayores de 46; y en el uso de computadores personales, estos índices por grupos etarios eran de $27 \%, 19 \%$, $13,7 \%$ y $6,3 \%$, respectivamente. ${ }^{16}$ Los datos sobre uso de telefonía celular e Internet en Chile y México también son elocuentes en cuanto a la mayor incidencia de población joven (gráfico 1). Si estas situaciones nacionales son extensibles a otros países de la región, podemos suponer que en el futuro la brecha generacional puede exacerbarse, dado que el uso de Internet genera no sólo diferencias de productividad, sino también asimetrías en la capacidad de interlocución, el acceso a información y conocimiento, el desarrollo cultural y otros aspectos. Por otra parte, los datos también revelan que la discriminación étnica se reproduce en el acceso a bienes audiovisuales e informáticos. La probabilidad de tener una computadora en el hogar es cinco veces mayor en el conjunto no indígena de la población que en los pueblos indígenas, y la probabilidad de tener un aparato de televisión es sólo dos veces más alto (gráfico 2).

La esperanza es que, pese a las diferencias, la velocidad de difusión de la conectividad en América Latina es hoy superior a la de cualquier otra región, y

\footnotetext{
16 Datos del Ministerio de Salud de Brasil, citados por Hilbert
} (2001b). 
Usuarios de teléfono celular en Chile

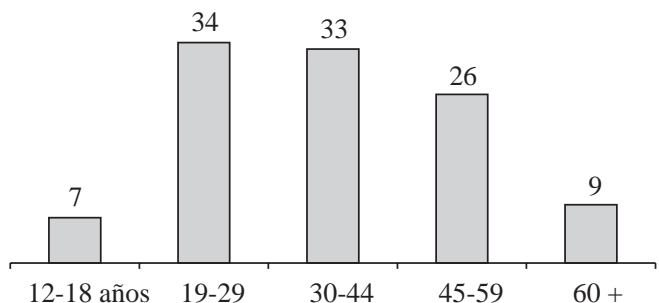

Usuarios de internet en México

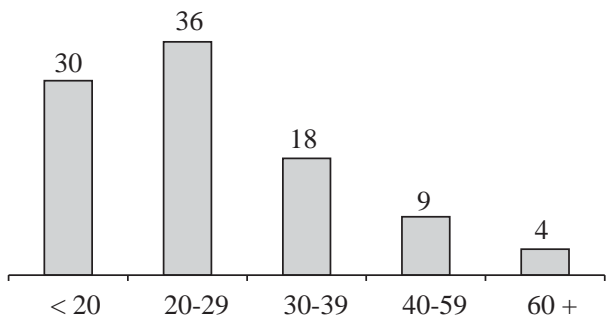

Fuente: SUBTEL (2002) y TNS (2002).

GRAFICO 2

Porcentaje de la población con computador/televisor en el hogar, por origen étnico, 2000

Computador

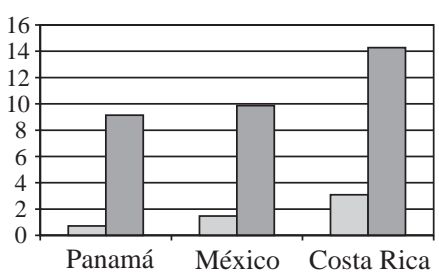

Televisor

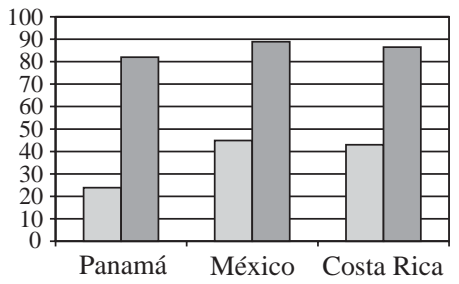

$\square$ Indígenas $\square$ No indígenas
Computador (zonas urbanas de México)

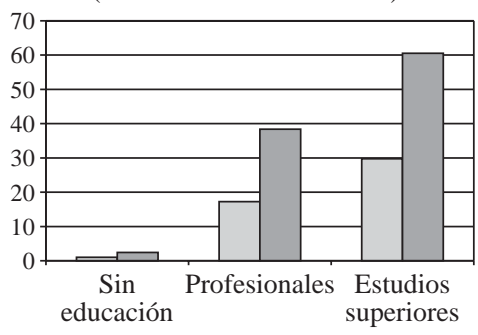

Fuente: Bases de microdatos de Panamá, México y Costa Rica, ronda de censos 2000.

la proporción entre acceso y equipamiento ha mejorado más que en otras regiones. En parte el problema del acceso a redes se reduce a medida que descienden los costos del equipamiento requerido en los hogares para acceder a microcomputadores e Internet, lo que permite que la conectividad se amplíe desde las familias de mayores ingresos hacia las de ingresos medios. Por otro lado, la necesidad de "democratizar" la conectividad, vale decir, difundirla a lo ancho de toda la sociedad, se enfrenta hasta ahora por tres vías. La primera es la de utilizar programas muy focalizados emprendidos por organizaciones no gubernamentales (ONG) y algunos programas estatales o municipales que conectan a grupos reducidos de manera todavía experimental. En América Latina los casos más citados son los de movimientos indígenas y organizaciones comunitarias que utilizan la red para expandir alianzas, tener presencia en el espacio público virtual, movilizarse políticamente y contar con mayor información sobre mercados, acceso a créditos y otros servicios.
Una segunda vía es la dotación de locales públicos donde se paga, a costos decrecientes, por navegar en la red. La tercera, y probablemente la de mayor potencial para la democratización del acceso, es la de los programas públicos de dotación de computadores en red en las escuelas públicas, en el marco de programas de reforma educacional que apuntan a incorporar el uso de redes electrónicas para el aprendizaje dentro de la educación formal. En estos últimos dos casos se parte de la premisa de que la era digital no se define tanto por la propiedad de los computadores, sino por el acceso a la red; el capital más importante sería el aprendizaje, no la máquina. En países como Perú el uso de Internet se está difundiendo, no por computadores en el hogar, sino por cafés y cabinas públicas de acceso; y en países como Brasil, Chile, Costa Rica y México, la expansión del número de usuarios se da por las redes instaladas en las escuelas. Si hoy Chile es el país latinoamericano con un mayor índice de conectividad, se debe fundamentalmente al éxito de su 
programa de instalación de terminales interconectados en todo el sistema educacional.

En América Latina la cobertura escolar es cercana al $100 \%$ en la educación primaria y está en rápida expansión en la secundaria. Es en la escuela donde los niños y jóvenes están institucionalizados y desarrollan diariamente sus procesos de aprendizaje y de interacción con sus pares. Por otro lado, las fuertes diferencias sociales y los altos índices de pobreza en muchos países de la región hacen que la gran mayoría de los hogares carezca de computador. Por lo mismo, es en las escuelas donde el acceso puede democratizarse. Además, el uso compartido de terminales en ellas permite sinergias positivas en términos de aprendizaje de lenguajes informáticos, agilidad y confianza en el uso del ciberespacio, y utilización de las redes electrónicas para procesar información y construir conocimientos relacionados con el currículo escolar. Socializar en redes debe ser parte de la tarea de socializar en las escuelas.

Existen ya en la región múltiples experiencias nacionales de equipamiento para medios interactivos en escuelas públicas, con éxito, cobertura y continuidad variables. Brasil ha impulsado el Programa Nacional de Informática en Educación (ProInfo) y, para el caso de medios de comunicación, el Programa Nacional de Educación a Distancia: TV Escuela, que apoya la actividad docente de la red pública de enseñanza en aspectos de metodologías, tecnologías de enseñanza y material de apoyo para el trabajo en la sala de clases, a través de un canal de televisión dedicado exclusivamente a la educación. En Costa Rica, el Programa de Informática Educativa, llevado a cabo desde 1988 por el Ministerio de Educación Pública y la Fundación Omar Dengo en todo el país, apunta a mejorar la calidad de la educación mediante el uso de computadores en la escuela primaria pública. En Chile, el proyecto Red Enlaces, desarrollado por el Ministerio de Educación, ha creado una red interescolar de comunicaciones a través de computadores entre alumnos, profesores y profesionales de otras instituciones relacionadas con la educación. Se inició en forma experimental en 1992, y en 2001 el $62 \%$ de las escuelas primarias del país y el $89 \%$ de los liceos de educación media ya estaban conectados a Internet a través del programa Enlaces. Otros países —entre ellos Argentina, Uruguay, México y Cuba - también están abocados a instalar y extender la conectividad escolar.

Respecto al camino recorrido por los programas de informática escolar emprendidos por países de la región surgen algunas interrogantes. La primera tiene que ver con la "densidad informática", vale decir, el número de alumnos que comparten un computador en las escuelas. Esto es clave, porque para familiarizarse con su uso y aprovecharlo bien es indispensable el acceso frecuente y personalizado. En Chile, que es uno de los países de mayor conectividad escolar, no ha sido fácil bajar el número de alumnos por computador: en 1998 se estimaba en 71 alumnos por computador, bajando a 65 en 2001 (Jara Schnettler y Pávez, 2001). En los Estados Unidos, la relación era de 1 por 125 alumnos en 1981 y se redujo a 1 por 5 en 2000 para el caso de computadores sin conexión multimedia, y a 10 por 1 en 2001 para computadores con conexión multimedia, actualizados y conectados a redes (Cuban, 2001). La segunda interrogante se refiere a la respuesta de los docentes, que suelen sentirse amenazados por la mayor celeridad con que los alumnos desarrollan destrezas computacionales y ven con angustia la brecha creciente entre cultura virtual y cultura pedagógica. Dados los niveles de ingresos de los maestros de escuela en América Latina, así como el poco tiempo libre que les queda para reciclarse, es poco probable que puedan familiarizarse con el computador por cuenta propia. Por lo tanto, es necesario que se les libere de algunas horas de trabajo y se los capacite en las propias escuelas, pues difícilmente cuentan con buenos equipos en los hogares. La tercera interrogante se relaciona con las posibilidades de llevar a cabo la actualización y mantención constantes de los equipos luego de instalarlos en las escuelas, pues eso supone una inversión continua que rebasa el alcance de los programas iniciales de dotación de equipos.

Entre otras lecciones aprendidas del caso chileno, y extensibles a otros contextos nacionales dentro de América Latina, destacan las siguientes (Jara Schnettler y Pávez, 2001). Primero, la introducción de las tecnologías de la información y la comunicación en el sistema escolar es un proceso lento, cuyo ritmo se asocia más a los tiempos largos del cambio cultural que a los períodos cortos de los gobiernos electos. Segundo, la innovación debe ser incremental y empática, por lo cual es preciso articular la difusión de esas tecnologías con las necesidades pedagógicas de los profesores, entregándoles herramientas (equipos, programas computacionales, guías) de fácil comprensión y uso. Tercero, la dotación de recursos y capacidades no puede ser homogénea en todo el sistema, sino que debe adaptarse a las distintas necesidades de profesores y estudiantes en escuelas con entornos de aprendizaje muy diversos. Y cuarto, es preciso coordinar este aspecto de las reformas educativas con otros, a fin de generar sinergias 
entre los programas de informatización escolar y los programas de bibliotecas de aula, de cambios en contenidos curriculares, de desarrollo del currículo transversal y otros.

Finalmente, tampoco es claro en qué medida la mayor dotación de computadoras, la mejor proporción entre número de alumnos y equipos, y una conectividad al alcance de todos, sean condiciones que aseguren que habrá saltos adelante en alfabetismo computacional, capacidades de aprendizaje y opciones futuras de mayor productividad laboral de los alumnos. Un estudio exhaustivo (Cuban, 2001) realizado en los Estados Unidos en el decenio de 1990 — la década de mayor equipamiento informático escolar del país- y prestando especial atención a Silicon Valley — la zona de mayor desarrollo informático- deja muchas dudas al respecto. Según su autor, es preciso tomar con cautela el entusiasmo de los empresarios y expertos que creen que más y mejores tecnologías computacionales en las escuelas permiten sincronizar los procesos de aprendizaje con los desafíos laborales en las modernas economías de mercado.

En dicho estudio se señala que durante las últimas dos décadas del siglo XX el gobierno federal estadounidense invirtió sumas sin precedentes en equipar con esas tecnologías a todas las escuelas públicas del país, con el apoyo ferviente de padres, ejecutivos de empresas, funcionarios públicos y educadores, democratizando así el acceso. Pero lo que no se ha confirmado en la práctica es el supuesto que tanto animó esas inversiones, a saber, que más acceso en las salas de clase conduce espontáneamente a más uso, a una pedagogía y aprendizaje más eficientes y mejores, y luego a mayor competencia laboral. Cuban señala, luego de una revisión profusa de los datos y la casuística, cuatro conclusiones que despiertan incertidumbre. La primera, es la falta de consenso efectivo respecto de lo que significa el alfabetismo computacional: si implica simplemente usar la computadora con programas básicos o si significa, por ejemplo, tener la capacidad de bajar programas, actualizar software y disco duro, etc. La segunda, es que en el decenio de 1990 Estados Unidos no exhibió grandes cambios en la calidad de la enseñanza y el aprendizaje, medidos por mayores logros académicos de estudiantes urbanos, suburbanos y rurales, que pudiesen atribuirse a un mayor acceso computacional. La tercera es que los profesores se mantienen en calidad de usuarios limitados y esporádicos de nuevas tecnologías en lo que se refiere a los métodos de enseñanza en las salas de clase, por más que usen el computador para fines admi- nistrativos. Y, finalmente, no está claro el impacto del equipamiento escolar en el acceso futuro a empleos de altos salarios, porque en general los alumnos mejor colocados posteriormente en el mercado laboral atribuyen las destrezas a usos de computadores fuera de la escuela (Cuban, 2001).

\section{Diferencias de sentido entre las tecnologías de información y comunicación, la cultura y la educación}

Las tecnologías que utilizamos para interactuar en el mundo virtual tienen una relación dialéctica con la cultura. Como señala Manuel Castells, muchos rasgos del paradigma informático, como son la interconexión, la porosidad y la flexibilidad, devienen también rasgos culturales (Castells, 1999, pp. 88-89). Por una parte, valores propios de la modernidad occidental encuentran su expresión paroxística en ese momento finisecular de masificación del intercambio en un mundo virtual: la velocidad de circulación, la expansión de interlocutores en la comunicación, la disipación de fronteras nacionales y de restricciones espaciales, la desagregación infinitesimal del conocimiento, la autonomía del sujeto que se resiste a las regulaciones exógenas y, como diría Paul Virilio, el relevo de la cosa pública por las imágenes públicas, de los rostros por los espectros. Como si las nuevas tecnologías de información y comunicación materializaran los rasgos propios de la posmodernidad o modernidad tardía. Pero al mismo tiempo el uso mismo de tales dispositivos tecnológicos, mientras navegamos por el espacio virtual, exacerba esas marcas culturales que le confieren un cierto destino a la tecnología. De este modo tecnología y cultura se van imbricando de manera dinámica.

Las nuevas ramas en la industria cultural y las tecnologías informáticas y comunicacionales redefinen radicalmente la comunicación, el acceso a la información y las formas de producir conocimientos. Tornan difusas las fronteras entre aprendizaje activo y recepción pasiva, entre roles de emisión y de recepción, entre cultura sedimentada (valores, religión, conocimientos heredados) y cultura contingente (videoclips, telenovelas, videojuegos, "chateo", etc.), entre alta y baja cultura, entre lo ilustrado y lo popular, entre lo nacional y lo exógeno. El régimen de rápida obsolescencia que rige los mercados e industrias culturales cambia la percepción de la gente respecto de qué, cuándo, dónde y para qué conocer y aprender. La información se hace tan accesible, inmediata, variada y detallada, que las figuras tradicionales del tutor o el 
maestro pierden sentido a los ojos de tantos niños que entran y salen en terminales de computadores como quien come o camina. La cultura se abre en su posibilidad de diálogo continuo en todas direcciones, descentrando sus lugares de producción y procesamiento.

Ante tal magnitud de cambios, la educación queda rápidamente en tela de juicio. No es fácil para el Estado hacerse cargo del campo educativo ante estas nuevas fuentes de información, cultura, conocimiento y entretención, donde se mezclan las funciones formativas/informativas de la industria cultural liviana con las de la industria cultural pesada. No hay una receta que diga cómo incorporar los nuevos medios en una rutina dentro del aula de clases; o cómo concertar operaciones conjuntas entre esta nueva oferta de la industria cultural y los desafíos de modernizar la educación en los sectores de ingresos bajos y medios bajos; o cómo concertar el personal docente (maestros, planificadores y "gerentes" de la educación) para su propio reciclaje en torno a estos desafíos; o cómo aprovechar la capacidad instalada, y su impacto en la vasta mayoría de los hogares, para poner en práctica programas de educación ambiental, educación del consumidor y educación para la paternidad responsable, entre otros.

Qué duda cabe: el uso de medios audiovisuales, así como el acceso a redes interactivas, constituye una herramienta poderosa para ampliar y democratizar oportunidades de aprendizaje entre grupos de distintos ingresos. La incorporación de soportes informáticos y audiovisuales es un gran aporte a la educación, en tanto enriquece los métodos de enseñanza y aprendizaje, torna accesible a alumnos y profesores todo tipo de conocimiento e información actualizados, revoluciona la capacitación docente, facilita la educación a distancia, torna más eficiente la gestión educacional y hace más participativos los procesos de aprendizaje.

Pero, por otro lado, la educación tiene que compatibilizar nuevas destrezas con un patrimonio acumulado en formación crítica. La euforia mediática no puede arrasar con la memoria pedagógica, y más bien debemos encontrar las formas de potenciar el aprendizaje con los nuevos dispositivos, sin que ello aniquile el sentido más profundo del aprender. Es cierto que una vez que la información se almacena en discos duros, el enciclopedismo puede resultar anacrónico. Pero no el humanismo al cual iba adherido. Hoy más que nunca se requiere espíritu crítico frente a la razón instrumental (en tanto razón que anula otras racionalidades); capacidad para discernir selectivamente entre las ven- tajas de las tecnologías de transmisión de mensajes y el riesgo de reducir el espíritu a la lógica de la mera transmisión; recelo frente a la sobredosis de estímulos mediáticos cuando se convierten en pura secuencia; asertividad personal para no desdibujarse en la seducción de tantas texturas que circulan por la superficie sin textura del monitor.

La educación encuentra aquí su límite y su posibilidad. Por una parte, capitalizar los nuevos insumos de aprendizaje para democratizar el acceso a la productividad, la ciudadanía, la comunicación y la diversificación de la vida cotidiana. Por otra, movilizar su propio patrimonio histórico para promover un uso de esos nuevos insumos que no implique ni el fin del sujeto ni la insoportable levedad del ser. No hay fórmulas claras entre lo que se debe desterrar y lo que se debe preservar en la pedagogía y en los currículos. En tiempos y espacios multimedia no es necesario internalizar la enciclopedia: basta saber buscarla en el monitor. Pero el monitor no enseña a apagar el monitor.

También está el drama de la escuela latinoamericana que no consigue asimilar las nuevas lenguas que los propios educandos traen a clases. La estrechez viene, pues, de lado y lado. Es necesario entender que "la transformación de los modos de leer... está dejando sin piso la obstinada identificación de la lectura con lo que atañe solamente al libro y no a la pluralidad y heterogeneidad de textos, relatos y escrituras (orales, visuales, musicales, audiovisuales, telemáticos) que hoy circulan" (Martín Barbero, 1996, p. 12). Y con razón señala Jesús Martín Barbero que la televisión rivaliza con la escuela en un sentido profundamente epistemólogico, pues mientras la televisión "deslocaliza" los saberes, los mezcla, los usa discontinua y espasmódicamente en aras de la entretención y los sustrae de la "institucionalidad" desde donde nacen, la escuela se mantiene en las antípodas: mensajes de larga temporalidad, sistematicidad, esfuerzo y disciplina. Más aún, la televisión es hoy el lugar del "desplazamiento de las fronteras entre razón e imaginación, entre saber e información, naturaleza y artificio, arte y ciencia, saber experto y experiencia profana" (Martín Barbero, 1996, p. 14). Para la escuela queda el desafío de salir de su posición defensiva frente al fenómeno de comunicación de masas, incorporar la plasticidad propia de dichos medios para difundir y combinar conocimientos, pero al mismo tiempo organizar este mosaico de estímulos mediáticos a fin de evitar la banalización del conocimiento y alimentar en el alumno un espíritu selectivo frente a aquello que Baudrillard llamó el éxtasis comunicacional. 
En este sentido, Orozco (1996) invita a superar las dos visiones antitéticas de la educación ante los medios de comunicación: sea la defensa de la audiencia frente a los medios, sea la aceptación acrítica de éstos como recursos para la modernización educativa. Propone a cambio una "pedagogía crítica de la representación", que abra en la sala de clases el debate sobre recepción de medios, asuma que la escuela es una institución entre otras que compiten por ejercer la hegemonía del conocimiento, infunda habilidades que permitan a los estudiantes expresarse en un entorno multimedia, y entienda la alfabetización como un proceso permanente que se liga a los distintos alfabetos de un mundo posmoderno-mediático, multicultural y de aceleración del cambio. ${ }^{17}$

En lo que se refiere a las nuevas tecnologías de información y comunicación, la educación enfrenta a largo plazo por lo menos tres grandes desafíos. En primer lugar, educar con nuevas tecnologías de información y conocimiento implica, en cierto modo, vincular su uso con la producción de sentido, tanto individual como colectivo. Dicha producción de sentido se nutre, a su vez, de la cultura propia. No se trata, por tanto, de transmitir una "euforia amnésica", sino de infundir el gusto y la responsabilidad por el encuentro entre cultura y tecnología, lo propio y lo exógeno, finalidad e instrumento. Al decir de Jesús Martín Barbero, la educación tiene que ser un espacio idóneo para pasar de los medios a las mediaciones.

En segundo lugar, la interacción virtual recurre a un hipertexto en que se mezcla la lectoescritura, la oralidad y la cultura por imágenes. Su inmediatez es oral, mientras su acción motriz básica es la digitación. La preeminencia de una sobre otra puede depender de la decisión del usuario según cómo visualiza la interlocución de turno a través de la pantalla. Puede privilegiar una comunicación letrada, acústica o visual según la ocasión y el efecto deseado. Sin duda esto impacta la forma de adquirir, procesar y difundir conocimientos. Si los currículos de la escuela están basados en la cultura letrada y en la compartimentación de géneros y materias, el hipertexto del intercambio virtual transgrede las fronteras y los compartimientos estancos. No se trata sólo de contenidos, sino principalmente de estilos de aprendizaje y enseñanza. Los cambios en las prácticas virtuales desafían, por lo mismo, las bases del sistema. ¿Cuánto cabe revolucionar el sistema de enseñanza para potenciar los aprendizajes en los

17 Véase Orozco, 1996. nuevos dispositivos de información y conocimiento? Ante esta pregunta no hay respuestas unívocas. Tal vez se impone necesariamente un cierto gradualismo en los cambios, dado que la formación docente y las prácticas pedagógicas no transitan al mismo ritmo que la innovación en las tecnologías de la información y la comunicación.

Por último, la interacción virtual oscila entre medio y fin. Si "chateamos", la comunicación es el objeto mismo y no hay nada que la trascienda; pero si buscamos una información científica para incorporar en nuestra investigación, la búsqueda virtual es sólo el medio. En este punto la educación también se encuentra, por decirlo así, entre el pedestal y el banquillo. En los niños y jóvenes de edad escolar el vínculo con la red tiende a ser lúdico y caótico, vale decir, se privilegia el "inmanentismo virtual" y no el potencial de la red para recabar conocimientos. Los riesgos en esta permutación de prioridades radican en la pérdida de capacidad para organizar conocimientos y ordenar las dinámicas de aprendizaje. El rol del profesor, como también de los planificadores de la enseñanza, deberá incluir la capacidad de brindar un contexto en el cual el uso de las tecnologías informáticas y comunicacionales en las escuelas mantenga una relación medios-fines en que la comunicación se oriente a adquirir y procesar conocimientos con sentido de totalidad y de manera ordenada. La reflexión crítica y una dosis saludable de enciclopedismo (bien entendido) tienen que estar en la base de las prácticas de aprendizaje con esas tecnologías. De lo contrario, se corre el riesgo de caer en una dispersión de actos comunicativos que no construyen ni sistematizan la información que van generando.

En síntesis: por un lado, no cabe duda de que es urgente incorporar ampliamente las tecnologías informáticas y comunicacionales en la educación, dado que es la forma más expedita, económica y masiva de reducir la brecha digital entre países y dentro de ellos. Si la inclusión social pasa cada vez más por el acceso al conocimiento, la participación en redes y el uso de tecnologías actualizadas de información y comunicación, el sistema de educación formal es la clave para difundir ese acceso. Pero, por otro, esto no significa que la "digitalización" de la educación nos ilumine en el conocimiento y libere a los educandos de los vestigios de la falsa conciencia y la ignorancia. Nada garantiza la forma en que se resuelven, computadora mediante, las tensiones entre cultura escolar y cultura juvenil, y entre razón instrumental y producción de sentido. Pero esas tensiones sólo se pueden resolver andando. Y para andar, hay que equipar a las escuelas. La educación 
enfrenta aquí su doble filo: movilizar la industria multimedia para ganar en motivación, en expresividad y en nuevas alfabetizaciones, pero al mismo tiempo no perder el espíritu crítico ni la sedimentación de la experiencia de aprendizaje. No hay fórmulas claras para el doble filo: sólo ensayo y error y aprender de la experiencia de otros.

\section{Interrogantes}

Sabemos que la mayor parte de las escuelas en la región adolece todavía de rezagos agudos en estilos pedagógicos y contenidos curriculares. Sabemos que la familiaridad con las redes virtuales es mucho más fácil en niños y adolescentes que en adultos, tal como lo es aprender un nuevo idioma. Sabemos que el costo de informatizar la educación pública permitiría, a lo sumo, una sala especial con terminales de red, pero no un uso intensivo-extensivo en el aula. Pero también sabemos que una vez que comienza a usarse la red digital, ese uso crece exponencialmente y tiene un enorme efecto de contagio; que el uso mismo produce cierta pericia y que ésta puede socializarse entre alumnos, y entre alumnos y profesores; y que el estudio en red no aniquila a la enciclopedia, sino que la hace accesible, amigable y adaptable a los gustos de los usuarios.

Por lo mismo, no hay un claro desenlace en este proceso que deberá poner en interacción la lógica de la red y la pedagogía masiva. Hay temor y entusiasmo, inseguridad y curiosidad, resistencia y apertura. Es un choque cultural con consecuencias prácticas. Sin duda la pedagogía basada en la memorización y en la presentación compartimentada del conocimiento no podrá sobrevivir a la facilidad con que se objetiva y amplía la memoria en un soporte informático, ni a la agilidad con que se relacionan datos y disciplinas heterogéneos en el trabajo en red.

Esto plantea, entre otras cosas, las tensiones que habrán de darse entre alumnos que adquieren destrezas en el manejo de la red y profesores que sienten que pierden autoridad en este proceso. ${ }^{18}$ También plantea

\footnotetext{
${ }^{18}$ En una investigación de la Facultad Latinoamericana de Ciencias Sociales (FLACSO), con estudios de casos realizados en varios países de América Latina, se encontró que "el intercambio informal que se genera entre los estudiantes durante las prácticas de informática, neutraliza y disminuye la capacidad de control del maestro", y que "el aula virtual es un vértice en el que chocan la actividad lúdica de los estudiantes y la autoridad vertical del maestro (...) el Internet marca el límite entre la experiencia dentro y fuera de la clase, dentro y fuera del orden educativo (...) entre la cultura del libro, concebida como una forma de relación, de control pedagógico sobre el
}

incertidumbres respecto de la calidad de segmentado del acceso, porque subsisten diferencias según el tipo de software instalado, los accesorios disponibles, la intensidad del acceso a Internet, y la capacitación recibida por los profesores. Más aún, mientras en algunos establecimientos escolares el uso de la computadora se restringe a ejercicios mecánicos de aplicación, en otros se optimiza su potencial de aprendizaje, experimentación, construcción de proyectos y trabajo cooperativo; y mientras unos usan Internet para juegos otros navegan para aprender (Trahtemberg, 2000, p. 10).

El uso cotidiano de las tecnologías de la información y la comunicación suscita problemas cuyo alcance aún no se conoce, como tampoco se conoce la forma de enfrentarlos, y que tienen que ver con valores, actitudes y expectativas de los niños y jóvenes que ocupan una parte importante de su tiempo frente a pantallas y monitores. Nuevas adicciones a juegos y a la información ligera, baja tolerancia a la frustración, poca disposición a diferir las gratificaciones, dificultad para racionalizar esfuerzos, resistencia a medios letrados de aprendizaje y a la investigación en profundidad y de larga duración sobre un mismo tema, deslegitimación de la autoridad de los profesores y otras figuras adultas, excesivo utilitarismo en la relación con el conocimiento, poca disposición a comunicarse cara a cara y menor capacidad de expresión oral, pueden ser algunos de los problemas que es preciso considerar. No faltan, en este sentido, voces de alarma: "La ya débil capacidad de comprensión lectora se debilitará cada vez más no sólo porque los alumnos leerán cada vez menos libros, sino porque aumentarán su lectura de mensajes breves y fraccionados como los que produce la navegación por Internet y los intercambios vía chat o correo electrónico" (Trahtemberg, 2000, p. 14).

Por lo mismo, es "prioritario resaltar otra vez los valores y la importancia de las actitudes, además de la indispensable adquisición de competencias, habilidades y conocimientos que ayuden al inviduo a desarrollar al máximo sus propios talentos para aplicarlos en la evolución positiva de las instituciones sociales" (Almada, 2000, p. 16). Investigaciones hechas por la FLACSO en varios países de América Latina sugieren que uno de los problemas respecto del impacto social de Internet en la cultura escolar es la tendencia a una implementación meramente instrumental o técnica que

estudiante, y nuevas formas de aprendizaje a través de las navegaciones por el ciberespacio emprendidas por los jóvenes..." (Bonilla, 2001, pp. 9-10). 
malogra su potencial como lenguaje y sistema de representaciones en que los jóvenes crean y recrean relatos, visiones de sí mismos y de la sociedad (Bonilla, 2001). Por otro lado, un estudio entre jóvenes escolares en Bogotá mostró que el uso de Internet en escuelas tendía a reducirse al sustituir electrónicamente el secular enciclopedismo escolar, reproduciendo pedagogías tradicionales del aprendizaje (ibíd.). En este sentido es necesario idear métodos de seguimiento y evaluación del uso de tecnologías informáticas y de comunicación en el proceso de aprendizaje en las escuelas, a fin de que tanto alumnos como profesores no sólo aprendan a usar las tecnologías, sino que también se formen criterios que orienten dicho uso a mejorar los aprendizajes, desarrollar espíritu crítico y combinar los aspectos lúdicos y formativos. ${ }^{19}$

Otras críticas a la aplicación de programas de dotación informática en el sistema educativo se refieren al rol y la capacitación de los docentes. Entre otras cosas se advierte que, a la hora de capacitar, los programas no definen el perfil del docente que se desea formar y no incorporan las tecnologías informáticas y comunicacionales a los currículos de formación y capacitación (Martínez Santiago, 2000). Se advierte igualmente que enseñar un curso en red es muy distinto a hacerlo en la forma tradicional, dado que los profesores deben alentar las interacciones de los participantes. Ello "requiere de los profesores pasarse el día contestando preguntas, monitoreando discusiones, realimentando", lo cual les exige "contactarse varias veces al día, leer las anotaciones de sus alumnos y contestarlas, sin contar la corrección de tareas y la revisión de los trabajos individuales o grupales que también requieren dedicación" (Trahtemberg, 2000, p. 6). Con esto los profesores deben ser al mismo tiempo aprendices de nuevos modos y contenidos, renovadores pedagógicos y facilitadores, todo esto frente a una herramienta nueva que los alumnos suelen aprender a usar con mayor celeridad que ellos.

También el uso de recursos audiovisuales convencionales dentro de la sala de clases, como la radio, el video y la televisión, debe difundirse cada vez más en las escuelas, lo cual nuevamente coloca a los profeso-

\footnotetext{
${ }^{19}$ Sin embargo, no es fácil evaluar los impactos y logros de programas de informática educativa, dado que los equipos y programas de información y las capacidades previas de los docentes en su uso varían de un establecimiento a otro, y porque es difícil distinguir los efectos del uso de las tecnologías de la información y la comunicación en escuelas donde se están realizando múltiples intervenciones (Jara Schnettler y Pávez, 2001).
}

res en una posición a la cual no están habituados. La experiencia muestra que la capacidad de atención, motivación y absorción de los educandos puede aumentar considerablemente cuando se utiliza apoyo audiovisual y se trabaja luego, en una estructura más horizontal y de conversación, a partir de ese material. A medida que se incorporen estos medios y la reflexión crítica sobre ellos la escuela podrá ir superando la oposición entre aprendizaje escolar y consumo mediático, estimulando en los alumnos un uso más selectivo y crítico del consumo cultural. El desafío para las escuelas, sobre todo las públicas, es salir de su postura defensiva frente al fenómeno de la comunicación masiva, incorporar la plasticidad propia de dichos medios para difundir y combinar conocimientos, pero a la vez organizar este mosaico de estímulos mediáticos a fin de evitar la banalización del conocimiento y alimentar en el alumno un espíritu selectivo.

El uso de tecnologías de la información y la comunicación en la escuela abre diversas perspectivas teóricas, que plantean interrogantes cuyas respuestas no son unívocas (Jara Schnettler y Pávez, 2001) ¿Son estas tecnologías sólo instrumentos de apoyo al proceso de aprendizaje o el motor de cambios pedagógicos y organizacionales, o son ambas cosas a la vez? ¿Quiénes son los agentes más adecuados para inducir cambios con el uso de tales tecnologías en las escuelas, y qué capacidades tecnológicas hay que promover allí para potenciar las tecnologías informáticas y comunicacionales y ser potenciados por ellas? ¿Qué lleva a promover el uso de esas tecnologías en las escuelas: resultados, motivaciones, procesos, capacidades? Lo cierto es que su uso tiene un sentido inmanente relacionado con el proceso mismo de aprendizaje y las motivaciones en dicho proceso: una finalidad intraescuela que tiene que ver con el cambio en las prácticas pedagógicas, y una clara finalidad extraescuela, que es la de formar oportunamente para desenvolverse en la sociedad del conocimiento.

Respecto a los procesos de aprendizaje en las escuelas, se argumenta que las tecnologías de la información y la comunicación hacen más sencilla la comprensión de conceptos clave en ciencias, lenguaje y matemáticas y permiten compenetrarse con la lógica de estas disciplinas mediante formas que permitan su asimilación más profunda e inmediata (interactividad, simulación, juego, modelamiento). Por lo tanto, capacitar en tales tecnologías es un fin en sí, porque constituyen mínimos indispensables en el mundo laboral y cultural de hoy y porque facilitan un aprendizaje más significativo del conjunto de saberes. Sin embargo, y como 
ya se señaló, la difusión de ellas en las escuelas tropieza con la complejidad y heterogeneidad de los sistemas educativos, con sus grandes diferencias en recursos informáticos, planes institucionales, preparación docente, prioridad otorgada a tales tecnologías y horas de uso en la jornada escolar, entre otros aspectos.

Por último, dotar a las escuelas de equipamiento audiovisual e informático es el comienzo de un proceso y no el centro de la transformación educativa. Educar para la sociedad de la información y el conocimiento es mucho más que cambiar libros por pantallas o monitores. Exige conjugar lo mejor de la tradición crítica y de la experiencia pedagógica con las nuevas opciones tecnológicas, y concertar la educación formal con las prácticas cotidianas de comunicación a distancia en una sociedad donde estas prácticas son cada vez más importantes, masivas y cruzadas. El camino es largo y pone a prueba a los planificadores, directores de escuela, docentes, alumnos, familias de los alumnos, creadores de software, comunicadores y estrategas de la industria cultural. Y de la sociedad reclama consensos amplios que trasciendan los ciclos de gobierno, tanto para garantizar continuidad en el proceso y logros cada vez mayores, como para recabar los recursos que permitan impulsar un salto adelante en educación y conocimiento a la altura de los desafíos aquí planteados.

\section{Bibliografía}

Almada, M. (2000): Sociedad multicultural de información y educación. Papel de los flujos electrónicos de información y su organización, Revista iberoamericana de educación, $\mathrm{N}^{\mathrm{o}} 24$, Madrid, Organización de Estados Iberoamericanos para la Educación, la Ciencia y la Cultura (OEI), septiembre-diciembre. Versión electrónica:www.campus-oei.org/revista/ rie24a05.htm.

Bonilla, M. (2001): Investigación del impacto sociocultural del Internet en América Latina y el Caribe en miras al diseño de políticas públicas de la comunicación y cultura equitativas, ponencia presentada al Seminario "América Latina hacia la era digital" (Santiago de Chile, CEPAL, 28 a 30 de noviembre).

Brunner, J.J. (1999): Cibercultura: la aldea global dividida, ponencia presentada en la Mesa Redonda sobre Cibercultura, Hannover, www.geocities.com/brunner_cl/cibercult.html.

Castells, M. (1999): La sociedad red, La era de la información: economía, sociedad y cultural, vol. 1, Madrid, Alianza Editorial, enero.

CEPAL (Comisión Económica para América Latina y el Caribe) (2000): Equidad, desarrollo y ciudadanía, LC/G.2071/Rev.1-P, Santiago de Chile. Publicación de las Naciones Unidas, $\mathrm{N}^{\circ}$ de venta: S.00.II.G.81.

(2003): Los caminos hacia una sociedad de la información en América Latina y el Caribe, LC/G.2195/Rev.1-P, serie Libros de la CEPAL, No 72 , Santiago de Chile, julio. Publicación de las Naciones Unidas, $\mathrm{N}^{\mathrm{o}}$ de venta: S.03.II.G.9.

CEPAL/UNESCO (Comisión Económica para América Latina y el Caribe/Organización de las Naciones Unidas para la Educación, la Ciencia y la Cultura) (1992): Educación y conocimiento: eje de la transformación productiva con equidad, LC/G.1702/ Rev.2-P, serie Libros de la CEPAL, $N^{o}$ 33, Santiago de Chile. Publicación de las Naciones Unidas, $\mathrm{N}^{\circ}$ de venta: S.92.II.G.6.

Cuban, L. (2001): Oversold and Underused: Computers in the Classroom, Cambridge, Massachusetts, Harvard University Press.

Cubides, H. (1998): El problema de la ciudadanía: una aproximación desde el campo de la comunicación-educación, Revista Nómadas, № 9, Bogotá, D.C., Universidad Central, septiembre.

Educ.ar (2001): www.educ.ar/educar/home/elproyecto.jsp.

Freire, P. y D. Macedo (1987): Literacy: Reading the Word and Reading the World, South Hadley, Massachusetts, Bergin \& Garvey Publishers, Inc.

García, H. y M. Pruyn (2001): Critical theory in education: remembering the lessons of El abuelito, Journal of Critical Postmodern
Organization Science, vol. 1, № 1, www.zianet.com/boje/tamara/ issues/volume_1/issue_1.

González, J.L. (2000): Perspectivas de la "educación para los medios" en la escuela de la sociedad de la comunicación, Revista iberoamericana de educación, $\mathrm{N}^{\circ} 24$, Madrid, Organización de Estados Iberoamericanos para la Educación, la Ciencia y la Cultura (OEI).Versión electrónica: www.campuesoei.org/revista/rie24a04.htm.

Hilbert, M. (2001a): Latin America on its Path into the Digital Age: Where Are We?, serie Desarrollo productivo, $\mathrm{N}^{\circ} 104$, LC/L.1555-P, Santiago de Chile, CEPAL, junio. Publicación de las Naciones Unidas, $N^{\circ}$ de venta: E.01.II.G.100.

(2001b): América Latina hacia la era digital, ponencia presentada al Seminario "América Latina hacia la era digital" (Santiago de Chile, CEPAL, 28 a 30 de noviembre).

(2003): Infrastructure, en M. Hilbert y J. Katz, Building an Information Society: A Latin American and Caribbean Perspective, LC/L.1845, Santiago de Chile.

Hopenhayn, M. y E. Ottone (2000): El gran eslabón: educación y desarrollo en el siglo XXI, Buenos Aires, Fondo de Cultura Económica.

Jara Schnettler, F. y A. Pávez (2001): Nuevas tecnologías y escuelas: aprendizajes y desafíos del Programa Enlaces de Chile, ponencia presentada al Seminario "América Latina hacia la era digital" (Santiago de Chile, CEPAL, 28 a 30 de noviembre).

Martín Barbero, J. (1996): Heredando el futuro. Pensar la educación desde la comunicación, Revista Nómadas, № 5, Bogotá, D.C., Universidad Central, septiembre.

Martínez Santiago, R. (2000): Introducción, Revista iberoamericana de educación, $\mathrm{N}^{\mathrm{0}}$ 24, Madrid, Organización de Estados Iberoamericanos para la Educación, la Ciencia y la Cultura (OEI), septiembre-diciembre. Versión electrónica: www.campus-oei.org/revista/rie24a00htm.

OCDE (Organización de Cooperación y Desarrollo Económicos) (2001): Encuesta internacional sobre alfabetización de adultos, http://www.unesco.org/education/uie/confintea/pdf/ 3d_span.pdf.

Orozco, G. (1996): Educación, medios de difusión y generación de conocimiento: hacia una pedagogía crítica de la representación, Revista Nómadas, № 5, Bogotá, D.C., Universidad Central, septiembre.

PNUD (Programa de las Naciones Unidas para el Desarrollo) (1999): Informe sobre el desarrollo humano, 1999, Nueva York, Okford University Press. 
PREAL (Programa de Promoción de la Reforma Educativa en América Latina y el Caribe) (2000): Mejores prácticas de política educacional y reforma educativa, http://www.preal.cl.

SubTEL (Subsecretaría de Telecomunicaciones de Chile) (2002): Informe estadístico 4. Caracterización socioeconómica de los servicios de telefonía y tecnologías de la información y comunicación, Santiago de Chile, http://www.subtel.cl.

Téllez, M. (1998): Desde la alteridad. Notas para pensar la educación de otro modo, Revista relea, $\mathrm{N}^{\circ} 5$, Caracas, Universidad Central de Venezuela, mayo-agosto.

TNS (Taylor Nelson Sofres) (2002): Latin America Online: Demographics, Usage \& Commerce, http://www.emarketer.com.

Touraine, A. (1997): ¿Podremos vivir juntos? Iguales y diferentes, Buenos Aires, Fondo de Cultura Económica.

Trahtemberg, L. (2000): El impacto previsible en las nuevas tecnologías en la enseñanza y la organización escolar, Revista iberoamericana de educación, $\mathrm{N}^{\circ}$ 24, Madrid, Organización de
Estados Iberoamericanos para la Educación, la Ciencia y la Cultura (OEI). Versión electrónica: www.campus-oei.org/revista/rie24a02.htm.

UNESCO (Organización de las Naciones Unidas para la Educación, la Ciencia y la Cultura) (1994): Medición de la calidad de la educación: resultados, serie Estudios, vol 3, Santiago de Chile, Oficina Regional de Educación de la UNESCO para América Latina y el Caribe (OREALC)/Red regional para la capacitación, la innovación y la investigación en los campos de la planificación y la administración de la educación básica y de los programas de alfabetización (REPLAD).

(2000a): Informe Regional de las Américas: Evaluación de Educación para Todos en el año 2000, www.unesco.cl/10.htm. (2000b), World Education Report 2000, París.

UIT (Unión Internacional de Telecomunicaciones) (2003): World Telecommunications Database, http://www.itu.int/ITU-D/ict/ statistics 
